\title{
Avaliação do estado de conservação de nascentes e suas Áreas de Preservação Permanente em Prosperidade, Vargem Alta, ES
}

Evaluation of the conservation status of sources and their Permanent Preservation Areas in Prosperidade, Vargem Alta, ES

Evaluación del estado de conservación de manantiales y sus Áreas de Preservación Permanente en Prosperidade, Vargem Alta, ES

Gabriel Permanhane da Silva

Pós-graduando em Agroecologia e Sustentabilidade, IFES, Brasil permanhaneg@gmail.com

Leticia Rigo Tavares

Pós-graduanda em Agroecologia e Sustentabilidade, IFES, Brasil leticiarigot@hotmail.com

Matheus Pereira Martins Graduando em Ciências Biológicas, UFES, Brasil maatpeer@gmail.com

\section{Helimar Rabello} Professor Mestre, Centro Universitário São Camilo, Brasil helimarbio@hotmail.com 


\section{RESUMO}

A Lei no 12.651/2012 do Novo Código Florestal estabelece a demarcação de um raio mínimo de 50 metros de vegetação natural ao redor de nascentes, se enquadrando como Áreas de Preservação Permanente (APPs), medida indispensável para a conservação dos recursos hídricos. O objetivo desse estudo foi realizar um levantamento, registro de impactos ambientais (positivos e negativos) e avaliação do estado de conservação de nascentes perenes e suas APPs inseridas em propriedades rurais, em Prosperidade, Vargem Alta, ES, sendo classificadas de acordo com o cumprimento em metros da faixa de vegetação no seu entorno e grau de perturbação (preservada, perturbada ou degradada). Foram catalogadas 18 nascentes, destas, apenas 1 preservada, 7 perturbadas e 10 degradadas. 0 maior contribuinte para a presença de impactos negativos e degradação das nascentes foi a atividade pecuária no espaço da APP, enquanto impactos positivos foram mais notáveis em ambientes de reflorestamento e agricultura. Constatase o desrespeito generalizado à lei de APPs no distrito, tornando-se emergencial o acompanhamento técnico junto aos proprietários para realizar a adequação ambiental a fim de preservar as nascentes.

PALAVRAS-CHAVE: Impactos ambientais. Vegetação ciliar. Recursos Hídricos.

\section{ABSTRACT}

Brazil's New Forest Code (Law no. 12.651), since 2012 establishes the demarcation of a minimum radius of 50 meters of natural vegetation around springs, classified as Permanent Preservation Areas (PPAs), an indispensable measure to the conservation of water resources. The objective of this study was to accomplish a survey, the record of environmental impacts (positives and negatives), and the evaluation of the conservation status of perennial springs and their PPAs inserted in rural properties, in Prosperidade, Vargem Alta, Espírito Santo State, Brazil, being classified according to the compliance in meters of the vegetation strip in their surroundings and degree of disturbance (preserved, disturbed, or degraded). Eighteen springs were cataloged, among these, only 1 preserved, 7 disturbed and 10 degraded. The largest contributor to the presence of negative impacts and degradation of the springs was the livestock activity in the PPA area, while positive impacts were more notable in reforested and agricultural environments. There is a generalized state of disrespect to the PPA's law in Prosperidade, being urgent a technical assistance with the owners to carry out the environmental adequacy in order to preserve the springs.

KEY WORDS: Environmental impacts. Riparian vegetation. Water resources.

\section{RESUMEN}

La Ley 12.651/2012 del Nuevo Código Forestal establece la demarcación de un radio mínimo de 50 metros de vegetación natural alrededor de los manantiales, siendo clasificado como Áreas de Preservación Permanente (APPS), una medida indispensable para la conservación de los recursos hídricos. El objetivo de este estudio fue realizar un levantamiento, registro de los impactos ambientales (positivos y negativos) y evaluación del estado de conservación de los manantiales perennes y sus APPs insertadas en propiedades rurales, en Prosperidade, Vargem Alta, ES, siendo clasificado de acuerdo con el cumplimiento en metros de la franja de vegetación en su entorno y grado de perturbación (preservado, perturbado o degradado). Se catalogaron 18 manantiales, entre estos, solo 1 preservado, 7 perturbados y 10 degradados. El mayor contribuyente a la presencia de impactos negativos y la degradación de los manantiales fue la actividad ganadera en el espacio de APP, mientras que los impactos positivos fueron más notables en los entornos de reforestación y agricultura. Existe una falta de respeto generalizada por la ley de APP en Prosperidade, lo que hace que el seguimiento técnico con los propietarios sea una emergencia para hacer ajustes ambientales con el fin de preservar los manantiales.

PALABRAS CLAVE: Impactos ambientales. Vegetación ribereña. Recursos hídricos. 


\section{INTRODUÇÃO}

Nascente ou olho d'água é o local onde aflora naturalmente a água subterrânea (CONAMA, 2002), através do qual se dá de forma mais direta o acesso aos recursos hídricos (FELIPPE e MAGALHÃES Jr., 2009).

A captação da água de nascentes por moradores é muito comum em zonas rurais, sendo a principal fonte para consumo (PALIVODA; POVALUK, 2015), isenta de licença pelos órgãos responsáveis conforme a Lei 9.433/1997 da Política Nacional de Recursos Hídricos. Segundo o Art. 225 da Constituição Federal (BRASIL, 1988), impõe-se ao poder público e à coletividade o dever de defender e preservar o meio ambiente para as presentes e futuras gerações, sujeitando infratores a sanções penais e administrativas.

As nascentes devem ter vegetação natural preservada em seu entorno, em um raio mínimo de 50 metros, qualquer que seja a topografia, em zonas rurais ou urbanas, constituindo-se como Áreas de Preservação Permanente (APPs), segundo a Lei no 12.651/2012 do Novo Código Florestal (BRASIL, 2012). Contudo, observa-se que muitos proprietários com nascentes em suas terras não respeitam a distância estabelecida para as APPs (DONADIO; GALBIATTI; PAULA, 2005). A mata ciliar cumpre uma função fundamental na interceptação, infiltração e manutenção da umidade no solo, contribuindo para a recarga dos aquíferos que, por sua vez, exfiltram na superfície como nascentes (BLINI; YOSO SAKAMOTO, 2013). As raízes e serapilheira presentes nas matas possibilitam a absorção de em média $70 \%$ do volume pluviométrico, normalizando a vazão dos corpos hídricos e contribuindo para a boa qualidade da água (SBPC; ABC, 2012). Funcionam ainda, como alternativa mitigadora dos impactos causados pela intervenção humana, atuando na diminuição e filtragem do escoamento superficial e do carregamento de sedimentos para os corpos hídricos (WAMMES et al., 2007).

A degradação de nascentes, além da ausência de vegetação ciliar, também está associada a fatores como atividades agrícolas, erosão dos solos, recuperação florestal incorreta e contaminação dos olhos d'água (PINTO, 2003). Para avaliar o grau de degradação, parâmetros qualitativos têm sido empregados como ferramenta para a implementação de estratégias conservacionistas (CUNHA; FERREIRA; 2019). Somado a isso, a avaliação do estado de conservação das nascentes permite analisar corretamente os impactos antrópicos, norteando a tomada de decisões futuras (PINTO et al., 2004).

\section{OBJETIVOS}

O presente trabalho teve como objetivo realizar um levantamento e caracterização ambiental de nascentes perenes e suas APPs presentes em propriedades rurais, em Prosperidade, no município de Vargem Alta, Espírito Santo.

\section{METODOLOGIA}

O trabalho foi desenvolvido na microbacia do Rio Fruteiras, no distrito de Prosperidade, pertencente ao munícipio de Vargem Alta - ES, entre os meses de julho e setembro de 2018. 0 Rio Fruteiras é um dos afluentes que compõem a bacia hidrográfica do Rio Itapemirim, caracterizando-o como importante produtor de água para a região. 
A população de Vargem Alta caracteriza-se como essencialmente rural, distribuindo-se em distritos, sendo Prosperidade um dos principais $\left(35,0 \mathrm{~km}^{2}\right.$ ) (INCAPER, 2011). Prosperidade possui atividades majoritariamente ligadas à extração e beneficiamento de mármore e cultivo de café, seguidos da pecuária de leite para subsistência e plantio de banana (INCAPER, 2020).

O clima da região é classificado como Cwa, clima subtropical úmido, verão chuvoso e inverno seco, conforme critérios adotados por Koppen (1948). A temperatura pode variar em média entre $9,4^{\circ} \mathrm{C}$ a $30,7^{\circ} \mathrm{C}$ (INCAPER, 2017). A vegetação predominante é Mata Atlântica de caráter secundário. $\mathrm{O}$ solo da região (85\%) é o latossolo vermelho amarelo distrófico e suas áreas estão distribuídas entre 600 e $900 \mathrm{~m}$ de altitude (INCAPER, 2011).

O estudo abrangeu nascentes perenes dentro dos limites do distrito de Prosperidade, localizadas através de busca ativa, contemplando apenas aquelas inseridas dentro de propriedades rurais, excluindo-se as localizadas em ambiente de mata nativa, de forma a concentrar as observações a respeito das APPs em ambiente antropizado.

As APPs das nascentes foram classificadas de acordo com o estado de conservação de sua vegetação, conforme a metodologia proposta por Pinto (2003), na qual a vegetação ao entorno da nascente é classificada como preservada, perturbada ou degradada, a partir de observações realizadas in locu.

A nascente que apresenta um raio mínimo de 50 metros de vegetação natural, como prevê a Lei no 12.651/2012 (BRASIL, 2012), com a ausência de sinais de perturbação ou degradação, é classificada como preservada. Uma nascente perturbada não apresenta um raio mínimo de 50 metros de vegetação natural, mas está em bom estado de conservação, mesmo sendo ocupada, em parte, por pastagem ou agricultura. A que não apresenta um raio mínimo de 50 metros de vegetação natural, com um elevado grau de perturbação, solo compactado, vegetação escassa e com erosão ou voçoroca, é classificada como degradada.

Foram apontados os impactos ambientais positivos e negativos constatados no espaço da APP de cada nascente, seguindo os parâmetros adaptados de Pinto, Roma e Balieiro (2012). As observações foram feitas em campo e registradas para posterior avaliação.

Os impactos positivos apurados foram: presença de cerca, presença de serapilheira, mata ciliar na APP, adoção de práticas conservacionistas, presença de fragmentos nativos próximos a APP e presença de sub-bosque. Já os negativos foram: constatação de focos de erosão, presença de atividade pecuária, uso de defensivos aplicados no entorno da nascente, acesso de animais domésticos ao olho d'água, presença de estrada, presença de taboa dentro da nascente e presença de lixo.

Em relação a forma de exfiltração, foram classificadas em pontuais (olhos d'água), quando a água passa da subsuperfície para a superfície em um ponto bem delimitado, ou difusas (brejos), quando a água aflora em uma área maior, sem um ponto de exfiltração bem definido (FARIA, 1997; VALENTE; GOMES, 2005).

A vazão foi aferida uma vez em cada nascente, entre os meses de agosto e setembro, contemplando a época mais seca do ano, excluindo ao máximo possível nascentes efêmeras dos resultados e minimizando distorções sazonais. A medição em L/s foi feita com auxílio de balde graduado de $5 \mathrm{~L}$, medidor graduado de $500 \mathrm{~mL}$, e sacos vazios, interceptando o curso d'água o mais à montante possível, dividindo-se o volume alcançado pelo tempo cronometrado, como 
realizado por Felippe e Magalhães Jr. (2009). A vazão é calculada pela Equação 1 (PINTO et al, 2004):

Sendo:

$$
\mathrm{Q}=[\Sigma(\mathrm{v} / \mathrm{t})] / \mathrm{n}(1)
$$

$\mathrm{Q}=$ vazão média observada $(\mathrm{L} / \mathrm{s})$

$\mathrm{v}=$ volume de água (em litros)

$\mathrm{t}=$ tempo (em segundos)

$\mathrm{n}=$ número de medições

As nascentes difusas sem fluxo a jusante não tiveram suas vazões mensuradas, sendo desprezadas, portanto, as vazões de três nascentes, sendo representadas nos resultados com ND (Não Detectado). Buscou-se confirmar em entrevista com moradores locais a perenidade das nascentes. $\mathrm{O}$ uso destinado a nascente também foi averiguado.

\section{RESULTADOS E DISCUSSÃO}

Foram catalogadas 18 nascentes, sendo 11 pontuais e 7 difusas. A menor vazão registrada foi de $0,003 \mathrm{~L} / \mathrm{s}$ e a maior, de 2,497 L/s, sendo esta última, fonte para abastecimento público. Três nascentes (N12, N13 e N15), todas de exfiltração difusa, não apresentaram vazão aferível. Em relação ao uso da água da nascente, predominantemente é destinada para o uso doméstico (8) e dessedentação do gado na pecuária (6) (Tabela 1).

Tabela 1: Longitude e Latitude, vazão, tipo de exfiltração e uso das nascentes de Prosperidade, Vargem Alta, ES.

\begin{tabular}{ccccc}
\hline Identificação & Longitude e Latitude & $\begin{array}{c}\text { Vazão } \\
\text { (L/s) }\end{array}$ & Tipo de exfiltração & Uso da nascente \\
\hline N1 & $20^{\circ} 40^{\prime} 05.5^{\prime \prime} \mathrm{S} 41^{\circ} 01^{\prime} 59.2^{\prime \prime} \mathrm{W}$ & 0,060 & Pontual & Uso doméstico \\
N2 & $20^{\circ} 40^{\prime} 03.5^{\prime \prime} \mathrm{S} 41^{\circ} 02^{\prime} 31.6^{\prime \prime} \mathrm{W}$ & 0,030 & Pontual & Uso doméstico \\
N3 & $20^{\circ} 39^{\prime} 13.0^{\prime \prime} \mathrm{S} 41^{\circ} 02^{\prime} 18.6^{\prime \prime} \mathrm{W}$ & 0,592 & Pontual & Uso doméstico \\
N4 & $20^{\circ} 38^{\prime} 44.0^{\prime \prime} \mathrm{S} 41^{\circ} 01^{\prime} 42.1^{\prime \prime} \mathrm{W}$ & 0,310 & Difusa & ND \\
N5 & $20^{\circ} 39^{\prime} 47.3^{\prime \prime} \mathrm{S} 41^{\circ} 03^{\prime} 45.2^{\prime \prime} \mathrm{W}$ & 0,021 & Difusa & Uso doméstico \\
N6 & $20^{\circ} 38^{\prime} 40.7^{\prime \prime} \mathrm{S} 41^{\circ} 03^{\prime} 34.4^{\prime \prime} \mathrm{W}$ & 0,024 & Pontual & ND \\
N7 & $20^{\circ} 38^{\prime} 33.7^{\prime \prime} \mathrm{S} 41^{\circ} 03^{\prime} 47.8^{\prime \prime} \mathrm{W}$ & 2,497 & Difusa & SAAE \\
N8 & $20^{\circ} 39^{\prime} 51.6^{\prime \prime} \mathrm{S} 41^{\circ} 03^{\prime} 38.2^{\prime \prime} \mathrm{W}$ & 0,103 & Pontual & Uso doméstico \\
N9 & $20^{\circ} 40^{\prime} 47.1^{\prime \prime} \mathrm{S} 41^{\circ} 03^{\prime} 46.3^{\prime \prime} \mathrm{W}$ & 0,473 & Pontual & Uso doméstico \\
N10 & $20^{\circ} 40^{\prime} 39.0^{\prime \prime} \mathrm{S} 41^{\circ} 03^{\prime} 41.3^{\prime \prime} \mathrm{W}$ & 0,048 & Pontual & ND \\
N11 & $20^{\circ} 40^{\prime} 31.7^{\prime \prime} \mathrm{S} 41^{\circ} 02^{\prime} 36.4^{\prime \prime} \mathrm{W}$ & 0,543 & Pontual & Uso doméstico \\
N12 & $20^{\circ} 40^{\prime} 22.8^{\prime \prime} \mathrm{S} 41^{\circ} 02^{\prime} 26.8^{\prime \prime} \mathrm{W}$ & $\mathrm{ND}$ & Difusa & Pecuária \\
N13 & $20^{\circ} 40^{\prime} 25.0^{\prime \prime} \mathrm{S} 41^{\circ} 02^{\prime} 26.0^{\prime \prime} \mathrm{W}$ & $\mathrm{ND}$ & Difusa & Pecuária \\
N14 & $20^{\circ} 39^{\prime} 47.4^{\prime \prime} \mathrm{S} 41^{\circ} 03^{\prime} 57.6^{\prime \prime} \mathrm{W}$ & 0,047 & Pontual & Pecuária \\
N15 & $20^{\circ} 40^{\prime} 38.7^{\prime \prime} \mathrm{S} 41^{\circ} 02^{\prime} 35.0^{\prime \prime} \mathrm{W}$ & $\mathrm{ND}$ & Difusa & Pecuária \\
N16 & $20^{\circ} 38^{\prime} 53.8^{\prime \prime} \mathrm{S} 41^{\circ} 03^{\prime} 52.3^{\prime \prime} \mathrm{W}$ & 0,154 & Difusa & Pecuária \\
N17 & $20^{\circ} 38^{\prime} 56.8^{\prime \prime} \mathrm{S} 41^{\circ} 03^{\prime} 56.4^{\prime \prime} \mathrm{W}$ & 0,053 & Pontual & Uso doméstico \\
N18 & $20^{\circ} 39^{\prime} 29.7^{\prime \prime} \mathrm{S} 41^{\circ} 02^{\prime} 57.8^{\prime \prime} \mathrm{W}$ & 0,003 & Pontual & ND \\
\hline
\end{tabular}

ND: Não detectado. SAAE: Serviço Autônomo de Água e Esgoto (abastecimento).

Fonte: Autores. 
A única nascente que apresentou faixa de vegetação natural de acordo com a legislação, foi a $\mathrm{N} 1$, sendo classificada como preservada (Figura 1 e Tabela 2).

Outras 7 nascentes foram classificadas como perturbadas, estando localizadas em pontos que variavam desde áreas de reflorestamento (N2 e N3), à transição entre mata nativa e agricultura ou pastagem (N4, N5, N6 e N7), bem como nascentes encontradas em meio a cafeicultura (N8). Todas as outras 10 nascentes se encontravam em um elevado grau de perturbação, solo compactado e vegetação ciliar praticamente ausente, sendo classificadas como degradadas. Na Tabela 2 são apresentados os impactos ambientais registrados em cada APP.

Figura 1: Mapa de localização e identificação das nascentes estudadas em Prosperidade, Vargem Alta - ES.
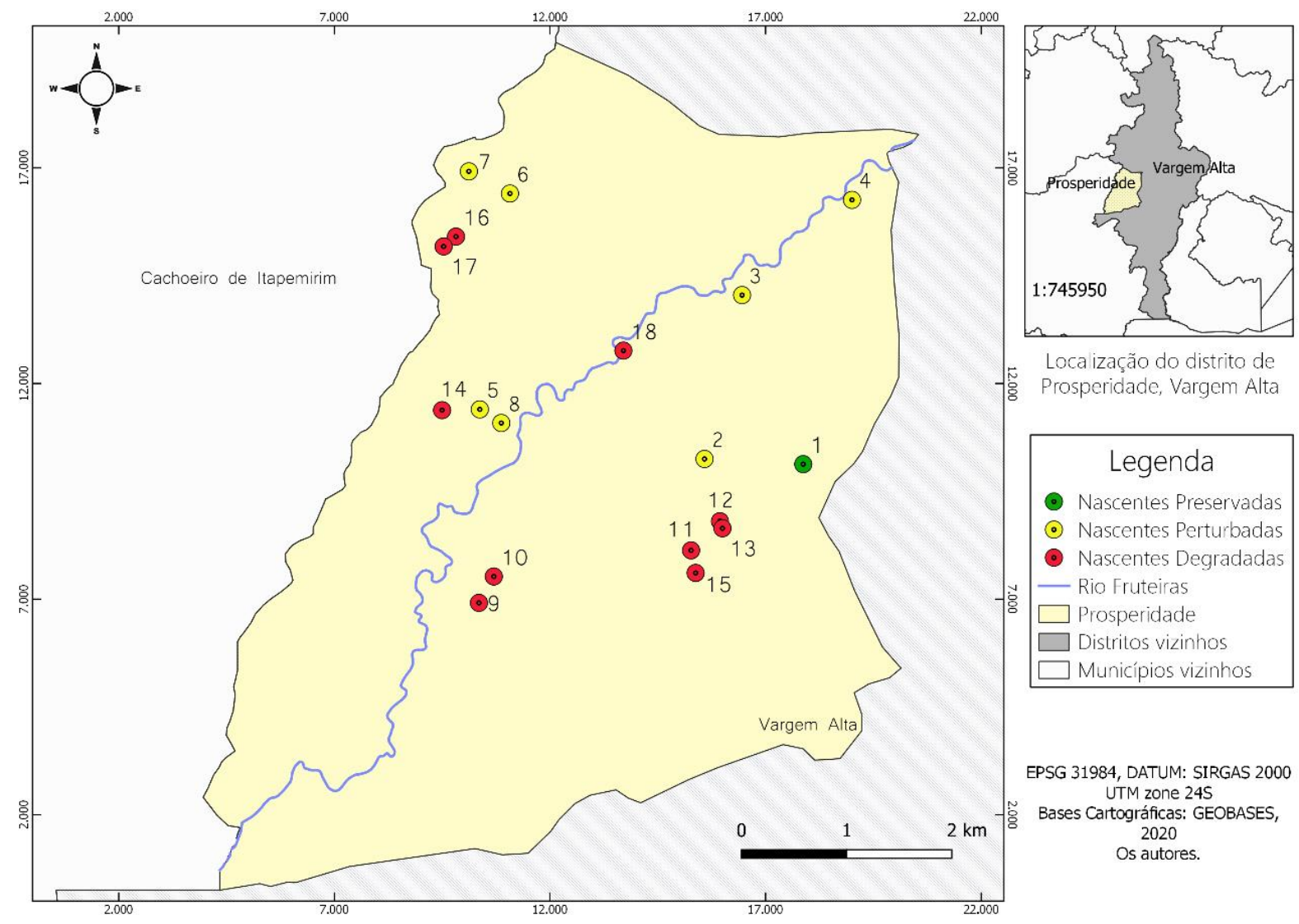

\section{Legenda}

- Nascentes Preservadas

- Nascentes Perturbadas

- Nascentes Degradadas

- Rio Fruteiras

$\square$ Prosperidade

$\square$ Distritos vizinhos

Municípios vizinhos

EPSG 31984, DATUM: SIRGAS 2000 UTM zone 245

Bases Cartográficas: GEOBASES,

$$
2020
$$

Os autores.

Fonte: Autores. 
Tabela 2: Presença (P) ou ausência (A) de impactos ambientais positivos e negativos no espaço das APPs e classificação das nascentes estudadas em Prosperidade, Vargem Alta, ES.

\begin{tabular}{|c|c|c|c|c|c|c|c|c|c|c|}
\hline Impactos & Parâmetros & N1 & N2 & N3 & N4 & N5 & N6 & N7 & N8 & N9 \\
\hline & Cerca & $P$ & $P$ & A & A & A & A & A & A & $A$ \\
\hline & Serapilheira & $P$ & $P$ & $P$ & $P$ & $P$ & $P$ & A & $P$ & $A$ \\
\hline & Mata Ciliar na APP & $P$ & $P$ & $P$ & A & A & A & A & A & A \\
\hline \multirow[t]{6}{*}{ Positivos } & Práticas conservacionistas & $P$ & $P$ & $P$ & $P$ & A & $A$ & $P$ & A & A \\
\hline & Fragmentos nativos próximos & $P$ & $P$ & $P$ & $P$ & $P$ & $P$ & $P$ & A & $P$ \\
\hline & Sub-bosque & $\mathrm{P}$ & $\mathrm{P}$ & A & A & A & A & A & A & A \\
\hline & Erosão & A & A & A & A & A & A & A & A & A \\
\hline & Atividade pecuária & A & A & $P$ & A & A & A & A & A & $A$ \\
\hline & Aplicação de defensivos & A & A & A & A & A & $P$ & A & A & A \\
\hline \multirow[t]{5}{*}{ Negativos } & Acesso de animais domésticos & A & A & $\mathrm{P}$ & A & A & A & $\mathrm{P}$ & $\mathrm{P}$ & $P$ \\
\hline & Presença de estrada & A & A & $P$ & $\mathrm{P}$ & $P$ & $P$ & $P$ & A & $P$ \\
\hline & Presença de taboa & A & A & A & $A$ & A & A & $\mathrm{P}$ & A & A \\
\hline & Presença de lixo & A & A & A & A & A & $\mathrm{P}$ & A & A & A \\
\hline & Classificação & $\mathrm{Pr}$ & $\mathrm{Pe}$ & $\mathrm{Pe}$ & $\mathrm{Pe}$ & $\mathrm{Pe}$ & $\mathrm{Pe}$ & $\mathrm{Pe}$ & $\mathrm{Pe}$ & $\mathrm{De}$ \\
\hline \multirow[t]{3}{*}{ Impactos } & Parâmetros & N10 & N11 & N12 & N13 & N14 & N15 & N16 & N17 & N18 \\
\hline & Cerca & A & A & $A$ & A & $A$ & A & A & A & A \\
\hline & Serapilheira & A & A & A & A & A & A & A & A & A \\
\hline \multirow[t]{7}{*}{ Positivos } & Mata Ciliar na APP & A & A & A & A & A & A & A & A & A \\
\hline & Práticas conservacionistas & A & A & A & A & A & A & A & $\mathrm{P}$ & A \\
\hline & Fragmentos nativos próximos & $P$ & $P$ & A & A & A & A & $\mathrm{P}$ & $P$ & A \\
\hline & Sub-bosque & A & A & A & A & A & A & A & A & A \\
\hline & Erosão & A & A & $P$ & $P$ & $P$ & $P$ & $P$ & A & A \\
\hline & Atividade pecuária & A & $\mathrm{P}$ & $\mathrm{P}$ & $\mathrm{P}$ & $\mathrm{P}$ & $\mathrm{P}$ & $P$ & $\mathrm{P}$ & $\mathrm{P}$ \\
\hline & Aplicação de Defensivos & A & A & A & A & A & A & A & A & A \\
\hline \multirow[t]{5}{*}{ Negativos } & Acesso de animais domésticos & $P$ & $P$ & $P$ & $P$ & $P$ & $P$ & $P$ & A & $P$ \\
\hline & Presença de estrada & $\mathrm{P}$ & $P$ & $P$ & $\mathrm{P}$ & A & $P$ & A & $\mathrm{P}$ & $\mathrm{P}$ \\
\hline & Presença de taboa & A & $P$ & $P$ & A & A & $P$ & A & A & A \\
\hline & Presença de lixo & A & A & A & A & A & A & A & A & A \\
\hline & Classificação & $\mathrm{De}$ & $\mathrm{De}$ & $\mathrm{De}$ & $\mathrm{De}$ & $\mathrm{De}$ & $\mathrm{De}$ & $\mathrm{De}$ & $\mathrm{De}$ & $\mathrm{De}$ \\
\hline
\end{tabular}

Pr: Preservada; Pe: Perturbada; De: Degradada.

FONTE: Autores.

Foi constatado que apenas duas nascentes ( $\mathrm{N} 1$ e N2) apresentam cercamento presente de forma efetiva, enquanto as outras 16 envolvidas no estudo continham cercamento parcial ou ausente (Tabela 2). O cercamento é determinado pela Lei no 12.651/2012 do Novo Código Florestal e deve ser instalado há um raio de 50 metros do olho d'água ou das bordas do brejo, havendo possibilidade de alterações dependendo do tamanho da propriedade. Esta medida visa a proteção da superfície do solo e a manutenção de condições para a recarga do lençol freático e a disponibilidade contínua de água em qualidade e quantidade (VIEIRA, 2016). O desrespeito a essa diligência acarreta diversos impactos negativos sobre a nascente e serão discutidos posteriormente.

Em apenas três nascentes (N1, N2 e N3) houve a presença de mata ciliar em toda a margem. Destas, apenas uma (N1) respeita o raio mínimo de 50 metros. A N2 apresenta uma faixa menor de cobertura florestal, variando entre 15 a 20 metros entre os quatro quadrantes $(N, S, L, O)$, 
embora possua uma margem sobressalente à mata ciliar, de pastagem desativada e cercada, em início do processo de regeneração natural. Nas duas nascentes, há extrato arbóreo superior e sub bosque e uma densa serapilheira. Ambas as nascentes sofreram a intervenção de um PRAD (Plano de Recuperação de Áreas Degradadas) em 2011 (VARGEM ALTA, 2011). A N3 se encontra em área reflorestada pelos proprietários ao longo das três últimas décadas, com espécies de grande porte, apresentando uma copa bem desenvolvida e boa produção de serapilheira. Apesar disso, há um razoável espaçamento entre as árvores, passagem de estrada e ausência de sub-bosque.

Apesar de algumas APPs se localizarem em regiões de transição entre mata nativa e lavoura ou pastagem (Tabela 3), nessas ocasiões, o ponto de exfiltração se encontra sempre no meio de cultura, ou ainda, sendo margeado apenas em algum dos quadrantes pela floresta, perdendo parte da efetividade de sua função protetora. Padrão semelhante de qualidade de preservação das nascentes e descumprimento da legislação é diagnosticado por Pinto et al. (2004), Palivoda e Povaluk (2015) e Vieira (2016).

Tabela 3: Descrição das APPs das nascentes estudadas em Prosperidade, Vargem Alta, ES.

\begin{tabular}{|c|c|}
\hline Nascente & Descrição da APP \\
\hline N1 & $\begin{array}{l}\text { Nascente inserida em APP reflorestada (PRAD) total }(\geq 50 \mathrm{~m}) \text {, devidamente cercada, com } \\
\text { vegetação densa bem desenvolvida. }\end{array}$ \\
\hline N2 & $\begin{array}{l}\text { Nascente inserida em fragmento de reflorestamento (PRAD) parcial }(<50 \mathrm{~m}) \text {, circundado } \\
\text { por área cercada em regeneração natural em início de processo. }\end{array}$ \\
\hline N3 & $\begin{array}{l}\text { Próxima a residências, com estrada particular de pouco movimento, parcialmente } \\
\text { reflorestada com árvores de duas a três décadas de idade, de dossel bem desenvolvido e } \\
\text { sem sub-bosque, com trechos de pastagem e cafeicultura. Livre acesso de animais. }\end{array}$ \\
\hline N4 & $\begin{array}{l}\text { Transição entre mata nativa com trechos em regeneração natural e cultivos agrícolas } \\
\text { diversos (café, banana, inhame, entre outros). Área cortada por estrada. }\end{array}$ \\
\hline N5, N6 & $\begin{array}{l}\text { Transição entre cafezal e mata nativa com trechos em estágio inicial de recuperação. } \\
\text { Trechos com passagem de estradas. }\end{array}$ \\
\hline N7 & $\begin{array}{l}\text { Manancial de maiores extensões, circundado por edificações e instalações rurais, com } \\
\text { trechos de mata nativa e cafeicultura nas margens, com represamento à jusante. }\end{array}$ \\
\hline N8 & $\begin{array}{l}\text { Localizada em meio à cafezal, sem cercamento. Ocorrência espontânea de espécies } \\
\text { nativas esparsas. }\end{array}$ \\
\hline $\mathrm{N} 9, \mathrm{~N} 10$ & $\begin{array}{l}\text { Inseridas em área de mineração de mármore, ocorrendo em meio à pequenas áreas de } \\
\text { macega, de livre acesso, cortadas por estradas públicas de grande movimento. }\end{array}$ \\
\hline N11 & $\begin{array}{l}\text { Transição entre área de instalações domésticas e pastagem, com formação de um } \\
\text { pequeno lago no olho d'água, sem cercamento, e área alagada mais à jusante. Cobertura } \\
\text { quase total das massas d'água por taboa (Typha domingensis). }\end{array}$ \\
\hline $\begin{array}{l}\text { N12, N13, N14, } \\
\text { N15, N16, N17 e } \\
\text { N18 }\end{array}$ & $\begin{array}{l}\text { Localizadas em pastagem, cortadas por estradas públicas e particulares, com cercamento } \\
\text { parcial ou ausente, e livre acesso para o gado. Forte presença de taboa (Typha } \\
\text { domingensis), e comum odor forte e cor escura da água. }\end{array}$ \\
\hline
\end{tabular}

FONTE: Autores.

Calheiros (2004) destacam a cobertura florestal como a de maior efeito positivo sobre as nascentes. A baixa densidade do solo, em decorrência da matéria orgânica apresenta um importante papel na taxa de infiltração de água (MINOSSO; ANTONELI; FREITAS, 2017), estabilização de agregados (SIX et al., 2000) e porosidade (SOUZA; LEITE; BEUTLER, 2004), e o 
sombreamento, na diminuição da temperatura (VALENTE; GOMES, 2005) e redução da evaporação (MINOSSO; ANTONELI; FREITAS, 2017).

Valente e Gomes (2005) e Firmino (2003) salientam a importância ecológica das matas ciliares enquanto detentoras de grande biodiversidade, por conta do ambiente heterogéneo que proporcionam, enquanto Spellerberg e Sawyer (1999) levantam o efeito da implantação de APPs na minimização da degradação dos fragmentos, através da criação de corredores ecológicos. Este é um ponto digno de futuros estudos, visto que 11 das nascentes possuem em seus arredores fragmentos de mata nativa, contudo, em sua maioria, com o raio de vegetação reduzido, perdendo a efetividade deste serviço ecossistêmico.

Foi observada, em geral, uma contribuição significativa da cobertura dos pés de café para a formação de serapilheira (N4, N5, N6, N8), influenciando no controle de impactos negativos, como a erosão. Além disso, observa-se uma constante ocorrência de espécies nativas crescendo espontaneamente junto às margens dos olhos d'água em meio aos cafezais. Percebe-se desta forma, a importância do cafezal enquanto cobertura vegetal na ausência da mata ciliar, já que 6 das nascentes possuem suas APPs parcial ou totalmente ocupadas pela cafeicultura.

Depois da cobertura florestal, áreas cultiváveis apresentam taxas mais elevadas de infiltração de água que a pastagem, devido a presença de vegetação e manejo constante do solo (MINOSSO; ANTONELI; FREITAS, 2017), plantas daninhas presentes enquanto barreira física para as gotas de chuva e levando em conta também a camada de matéria orgânica no solo, tornandoo menos denso, como também salienta Brinate et al. (2008).

Só houveram seis nascentes que apresentassem algum tipo de iniciativa conservacionista por parte dos usuários, destacando-se praticas vegetativas, como aquela promovida através do PRAD sobre N1 (Figura 2) e N2; e mecânicas, em geral, isolando o ponto de exfiltração.

Destaca-se uma tentativa falha de proteção vegetativa na nascente N11, onde foi demarcado um pequeno fragmento florestal, cercado, no qual se encontrava o olho d'água há alguns anos. Com o passar do tempo, este ponto de exfiltração "migrou" alguns metros no terreno, saindo do campo de proteção deste fragmento, estando atualmente totalmente exposto à pastagem. Em conversa com moradores, de modo geral, percebe-se uma consciência coletiva em relação à importância da vegetação para as nascentes, embora alguns conceitos se apresentem distorcidos, como uma preferência pela bananeira para o plantio ao redor de nascentes devido à supostos efeitos benéficos desta planta. De fato, observa-se uma forte presença da banana em meio aos cafezais, principalmente mais próximo ao olho d'água. Estas informações equivocadas podem ser obstáculo para a implementação de práticas vegetativas efetivas, ainda que aplicadas informalmente.

Apenas três nascentes (N4, N14, N17) apresentaram algum modelo de proteção aos olhos d'água, uma adaptação de EPAGRI (2004) do método caxambu, sendo de maneira improvisada e notadamente sem suporte técnico. Essas estruturas, de acordo com o observado in locu, cumprem o papel de isolar o olho d'água, protegendo a água e a distribuindo através canos e mangueiras para caixas d'água coletivas ou diretamente para residências. 
Em 9 nascentes foi verificada a presença de atividade pecuária na APP, em sua maioria localizadas em pastagem e sendo destinadas como alternativa de bebedouro para o gado, como retratado na Figura 3.

Figura 2: Espaço interno da APP da N1 (preservada)

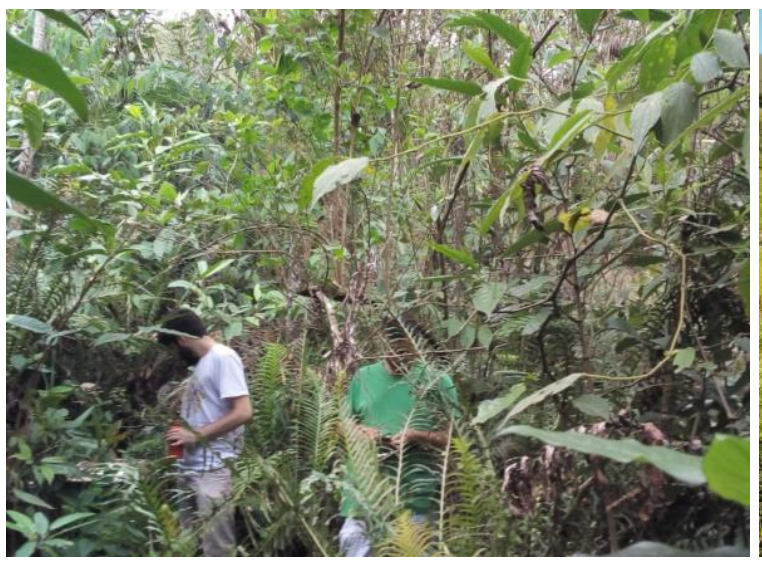

Fonte: Autores.
Figura 3: Espaço interno da APP da N12 (degradada)

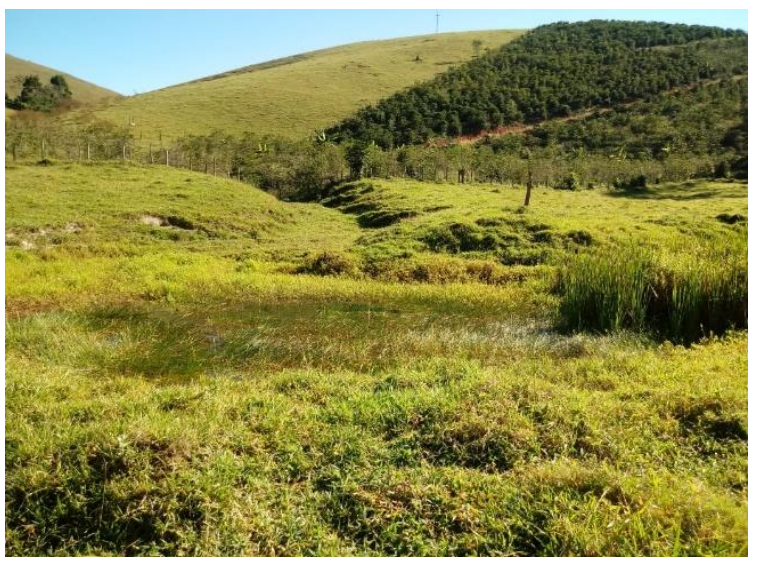

Fonte: Autores.

De acordo com Pinto (2003), as nascentes ao redor das quais há pastagem com presença de animais, ficam submetidas a prejuízos nos processos posteriores de regeneração natural, pois o pisoteio do gado contribui para a quebra de plântulas. Solos sob pastagem também tendem a apresentar maior densidade ocasionada pelo pastejo do gado e uso extensivo, dificultando a infiltração da água no solo, cujo movimento vertical também é prejudicado pelas raízes das gramíneas, fatores acentuados pela ausência de rotatividade, prejudicando a recarga das nascentes (PINHEIRO; TEIXEIRA; KAUFMANN, 2009; LIMA et al., 2010).

$\mathrm{Na} \mathrm{N} 14$ e N15 era nítido o pisoteio dentro das nascentes e alto processo erosivo, além da presença de estrume, com potencial de contaminação por patógenos (CRUVINEL, 2011).

O contato com animais domésticos também pode ocorrer fora do ambiente de pastagem, em qualquer nascente desprotegida, como por aves de criação, como observado na N3, por exemplo, o que torna urgente a tomada de medidas conservativas.

É possível que, mesmo em um contexto de pecuária, não haja o contato direto de animais com o afloramento, como na $\mathrm{N} 17$, onde o proprietário manilhou o olho d'água, isolando-o com tampa de concreto. Desta forma, a água captada por canos e mangueiras e destinada para o uso doméstico não sofre contaminação pelos animais, e o olho d'água não sofre pisoteamento direto, ainda que os animais tenham acesso ao fluxo de água superficial à jusante.

Em 13 das nascentes, há a passagem de estradas vicinais dentro do raio de APP, na maioria delas, havendo grande movimento de veículos. Em todos esses casos, inexiste cercamento isolando a nascente, apenas divisas entre a propriedade e a estrada, no caso de passagens públicas. Pinto, Roma e Balieiro (2012) descrevem a contribuição dessas estradas para processos erosivos e para a vulnerabilidade causada pelo tráfego intenso. 
A alteração contínua do solo causada por práticas agrícolas, rastros de trilhas e pisoteio das margens desprotegidas dos rios, podem ser razões para a erosão e o consequente transporte de sedimentos aos cursos hídricos (SIMÕES, 2001). Em todas as nascentes onde a presença de erosão foi constatada (N12, N13, N14, N15 e N16) havia atividade pecuária no entorno.

Pôde-se perceber ainda, um forte domínio da taboa (Thypha domingensis Pers) em quatro das nascentes difusas (N7, N11, N12 e N15). A presença dessa espécie é um contribuinte para a degradação, diminuindo a vazão da nascente e tornando a água estagnada, além de contaminar pela decomposição dos restos vegetais, aumentando o teor de matéria orgânica da água e intensificando o desenvolvimento de microorganismos (MARMONTEL; RODRIGUES, 2015).

Não foi observada, em geral, presença de lixo nas APPs, tendo apenas a N6 como exceção. À poucos centímetros do olho d'água foi encontrada uma embalagem descartada do fungicida Simboll 125 SC. Destinado ao combate à Ferrugem (Hemileia vastatrix), carrega o caráter de altamente persistente no meio ambiente (Classe III), com aplicação recomendada a $250 \mathrm{~m}$ de distância de mananciais (Informações da bula).

Pinto (2012) atenta para o emprego de defensivos agrícolas nas áreas de atividade agropecuária, com efeitos comprovados sobre os níveis de oxigênio e fosfato dissolvidos na água. Foi possível constatar o uso de defensivos apenas na N6, por meio da presença da embalagem do produto, porém, exames químicos da água podem denunciar a presença de agroquímicos em outras nascentes inseridas em meio a lavouras, já que os proprietários podem negar a utilização.

Em suma, somente a N1 e N2 tiveram a presença de todos os impactos positivos. As nascentes N12, N13, N14, N15 e N18 marcaram ausência para todos os impactos positivos.

Os impactos positivos mais frequentes foram a presença de fragmentos nativos próximos a APP (12), embora apenas 3 das nascentes apresentem mata ciliar, reduzindo a funcionalidade ecológica deste aspecto e a presença de serapilheira (7), principalmente em ambiente de reflorestamento e cafeicultura. Os mais raros foram a presença de cercamento (2) e de subbosque (2).

Os impactos negativos mais frequentes foram a presença de estradas vicinais na APP (13) e o acesso de animais domésticos ao olho d'água (12), principalmente devido à ausência de cercamento e localização em ambiente de atividade pecuária. Os impactos negativos menos registrados foram a presença de lixo (1) e aplicação de defensivos na APP (1), ainda que ocorram concomitantemente no único caso encontrado (N6).

\section{CONCLUSÕES}

Foram catalogadas ao todo 18 nascentes. Apenas uma nascente neste estudo (N1) se encontra preservada, estando em conformidade com a Lei no 12.651/2012 do Novo Código Florestal. Sete (N2, N3, N4, N5, N6, N7, N8) se encontram perturbadas e dez degradadas (N9, N10, N11, N12, N13, N14, N15, N16, N17 e N18).

O tipo de ocupação que predominou sobre as APPs das nascentes foi a pastagem (8), seguida da agricultura (6), sendo a presença da pastagem e da pecuária, sem cercamento, as causas mais significativas dos impactos negativos sobre as nascentes e do estado de degradação, causando o assoreamento e contaminação da água. 
A partir dos resultados encontrados, se mostra urgente a atuação técnica junto à população local afim de divulgar a legislação ambiental vigente no que diz respeito a nascentes e encontrar meios de pô-la em prática, visto sua importância no abastecimento doméstico no distrito e alimentação dos corpos hídricos.

\section{REFERÊNCIAS BIBLIOGRÁFICAS}

BLINI, Rony; YOSO SAKAMOTO, Arnaldo. ANÁLISE AMBIENTAL DO CÓRREGO ARROZ DOCE SELVIRIA/MS. Periódico Eletrônico Fórum Ambiental da Alta Paulista, [S.I.], v. 9, n. 2, nov. 2013. Disponível em: <https://www.amigosdanatureza.org.br/publicacoes/index.php/forum_ambiental/article/view/654/678>. Acesso em: 25 Jan. 2020. doi:http://dx.doi.org/10.17271/19800827922013654.

BRASIL. Lei 12.651, de 25 de Maio de 2012. Novo Código Florestal Brasileiro. 2012. Disponível em: <http://www.planalto.gov.br/ccivil_03/_ato2011-2014/2012/lei/l12651.htm>. Acesso em: 09 jan. 2019.

BRASIL. Constituição (1988). Constituição da República Federativa do Brasil. Brasília, DF: Senado Federal: Centro Gráfico, 1988.

BRINATE, S. V. B.; NOGUEIRA, N. O.; MARTINS, L. D.; TOMAZ, M. A.; ANDRADE, F. V.; PASSOS, R. R. Avaliação dos atributos físicos de solos sob cultivo de café na microrregião do Caparaó - ES. In: XII Encontro Latino Americano de Iniciação Científica e VIII Encontro Latino Americano de Pós-Graduação - Universidade do Vale do Paraíba, 2008. Disponível em: <http://www.inicepg.univap.br/cd/INIC 2008/anais/arquivosINIC/INIC0928_03_A.pdf>. Acesso em: 12 jan. 2019.

CALHEIROS, R. O. Preservação e Recuperação de Nascentes (de água e de vida). Piracicaba: Comitê das Bacias Hidrográficas dos rios PCJ - CTRN, 2004, 40p. Disponível em: <http://www.institutohomempantaneiro.org.br/arquivos/Cartilha_CBH.pdf>. Acesso em: 15 jan. 2019. CONSELHO NACIONAL DO MEIO AMBIENTE (CONAMA). Resolução CONAMA no 303 de 20 de março de 2002. Diário Oficial da União, Brasília, DF, 13 de maio de 2002, Seção 1, página 68.

CRUVINEL, C. E. O. Diagnóstico ambiental e plano de recuperação de uma nascente Rio Verde, GO. Trabalho Final de Graduação (Engenharia Ambiental) - Fesurv - Universidade de Rio Verde, 2011, 12 p. Disponível em: <http://www.unirv.edu.br/conteudos/fckfiles/files/DIAGNOSTICO\%20AMBIENTAL\%20E\%20PLANO\%20DE\%20RECU PERACAO\%20DE\%2OUMA\%20NASCENTE.pdf>. Acesso em: 31 mar. 2019.

CUNHA, C. L. N.; FERREIRA, A. P. Análise crítica por comparação entre modelos de qualidade de água aplicados em rios poluídos: contribuições à saúde, água e saneamento. Revista Engenharia e Sanitária Ambiental, v.24, n.3, p.473480, 2019. Disponível em: <http://www.scielo.br/scielo.php?script=sci_arttext\&pid=S1413-41522019000300473>. Acesso em: 31 mar. 2019. https://doi.org/10.1590/s1413-41522019112332.

DONADIO, N. M. M.; GALBIATTI, J. A.; PAULA, R. C. Qualidade da água de nascentes com diferentes usos do solo na bacia hidrográfica do córrego Rico, São Paulo, Brasil. Engenharia Agrícola, Jaboticabal, v.25, n.1, p.115-125, 2005. Disponível em: <http://www.scielo.br/pdf/eagri/v25n1/24877.pdf>. Acesso em: 18 jan. 2019.

EPAGRI (Empresa de Pesquisa Agropecuária e Extensão Rural de Santa Catarina). Água da fonte: proteção de fonte modelo Caxambu - como fazer a proteção. Florianópolis: Epagri, 2004, 6 p.

FARIA, A. P. A dinâmica de nascentes e a influência sobre os fluxos nos canais. A Água em Revista, Rio de Janeiro, v. 8, p.74-80, 1997.

FELIPPE, M. F.; MAGALHÃES Jr., A. P. Análise da variabilidade da vazão das nascentes no Parque das Mangabeiras (Belo Horizonte - MG) em relação aos seus condicionantes ambientais. In: XIII Simpósio Brasileiro de Geografia Física Aplicada, Viçosa MG, Brasil. Anais do... Viçosa: Universidade Federal de Viçosa, 2009. Disponível em: $<$ http://www.geomorfologia.ufv.br/simposio/simposio/trabalhos/trabalhos completos/eixo3/071.pdf>. Acesso em: 20 jan. 2019. 
FIRMINO, W. G. Análise do Impacto da Ação Antrópica na Microbacia do Córrego Lava-Pés em Ipameri - Goiás. Pires do Rio: UEG. Monografia de graduação, Universidade Estadual de Goiás -UEG, 2003.

INSTITUTO CAPIXABA DE PESQUISA, ASSISTÊNCIA TÉCNICA E EXTENSÃO RURAL (INCAPER). Programa de assistência técnica e extensão rural PROATER 2011 - 2013. Vargem Alta, 2011. Disponível em: <https://incaper.es.gov.br/media/incaper/proater/municipios/Caparao/Vargem_Alta.pdf>. Acesso em: 20 jan. 2019.

INSTITUTO CAPIXABA DE PESQUISA, ASSISTÊNCIA TÉCNICA E EXTENSÃO RURAL (INCAPER). ZONAS NATURAIS DO ESPIRITO SANTO: uma regionalização do Estado, das microrregiões e dos municípios. 2017. Disponível em: $<$ https://meteorologia.incaper.es.gov.br/Media/Hidrometeorologia/documentos/climadosmunicipios. pdf\#page=86 >. Acesso em: 20 jan. 2019.

INSTITUTO CAPIXABA DE PESQUISA, ASSISTÊNCIA TÉCNICA E EXTENSÃO RURAL (INCAPER). Informação verbal do escritório do desenvolvimento rural de Vargem Alta, 2020.

KÖPPEN, W. Climatologia: com um estúdio de los climas de la tierra. México: Fondo de Cultura Econômica, 1948, $479 \mathrm{p}$.

LIMA, G. C.; SILVA, M. L. N.; SILVA, M. A.; OLIVEIRA, A. H.; FREITAS, D. A. F.; MARQUES, R. M.; SANTOS, E. A.; PEREIRA, P. H. Relações entre resistência do solo à penetração, permeabilidade do solo à água e recarga de água para um neossolo litólico sob diferentes usos, na sub-bacia das Posses, Extrema (MG). In: XXXIII Congresso Brasileiro de Ciência do Solo, 2010.2 Disponível em: https://extrema.mg.gov.br/conservadordasaguas/wpcontent/uploads/2019/07/A.Cient .ResumoCBCS permeabilidade-e-resistencia-a-penetracao-nas-posses.pdf. Acesso em: 5 out. 2019.

MARMONTEL, C. V. F.; RODRIGUES, V. A. Avaliação qualitativa de nascentes com diferentes coberturas do solo e conservação da vegetação em seu entorno no córrego Pimenta. Scientia Agraria Paranaensis - SAP; ISSN: 1983-1471 Marechal Cândido Rondon, v. 14, n. 1, p. 53-59, 2015. Disponível em: <http://erevista.unioeste.br/index.php/scientiaagraria/article/view/9540>. Acesso em: 13 mar. 2019. http://dx.doi.org/10.18188/sap.v14i1.9540.

MINOSSO, J.; ANTONELI, V.; FREITAS, A. R. Variabilidade sazonal da infiltração de água no solo em diferentes tipos de uso na região Sudeste do Paraná. Revista Geographia Meridionalis, v. 03, n. 01, p. 86-103, 2017. Disponível em: <https://periodicos.ufpel.edu.br/ojs2/index.php/Geographis/article/view/11041/7261>. Acesso em: 8 set. 2019.

PALIVODA, A. P.; POVALUK, M. Avaliação do estado de conservação de nascentes localizadas em áreas rurais do município de Itaiópolis, SC. Saúde Meio Ambiente, v. 4, n. 1, p. 17-31, 2015. Disponível em: <http://www.periodicos.unc.br/index.php/sma/article/view/609/546>. Acesso em: 20 jan. 2019.

PINTO, L.V.A. Caracterização física da bacia do ribeirão Santa Cruz, Lavras, MG, e propostas de recuperação de suas nascentes. Dissertação (Mestrado em Engenharia Florestal/Manejo Ambiental) - Universidade Federal de Lavras, Lavras, 2003, 165 p. Disponível em: < http://repositorio.ufla.br/jspui/handle/1/28095>. Acesso em: 31 abr. 2019.

PINTO, L. V. A. BOTELHO, S. A.; DAVIDE, A. C.; FERREIRA, E. Estudo das nascentes da bacia hidrográfica do Ribeirão Santa Cruz, Lavras, MG. Scientia Forestalis, n.65, p.197-206, 2004. Disponível em: <https://www.ipef.br/publicacoes/scientia/nr65/cap19.pdf>. Acesso em: 20 jan. 2019.

PINTO, L. V. A.; ROMA, T. N.; BALIEIRO, K. R. C. Avaliação qualitativa da água de nascentes com diferentes usos do solo em seu entorno. Cerne, Lavras, v. 18, n. 3, p. 495-505, 2012. Disponível em: <http://www.scielo.br/scielo.php?pid=S0104-77602012000300018\&script=sci_abstract\&tlng=pt>. Acesso em: 31 mar. 2019. https://doi.org/10.1590/S0104-77602012000300018.

PINHEIRO, A.; TEIXEIRA, L. P.; KAUFMANN, V. Capacidade de infiltração de água em solos sob diferentes usos e práticas de manejo agrícola. Revista Ambiente e Água, v.4, n. 2, p. 188- 199, 2009. Disponível em: < https://www.redalyc.org/articulo.oa?id=92811747017>. Acesso em: 31 mar. 2019. https://doi.org/10.4136/ambiagua.97.

SBPC; ABC - Sociedade Brasileira para o Progresso da Ciência; Academia Brasileira de Ciências. 0 Código Florestal e a Ciência: Contribuições para o Diálogo. 2. ed., -São Paulo: SBPC, 2012, 294 p. 
SIMÕES, L.B. Integração entre um modelo de simulação hidrológica e sistema de informação geográfica na delimitação de zonas tampão ripárias. Tese (Doutorado em Agronomia/Energia na Agricultura). Faculdade de Ciências Agronômicas, Universidade Estadual Paulista, Botucatu, 2001, 168 p.

SIX J, PAUSTRIAN K,; ELLIOTT E. T.; COMBRINK, C. Soil Structure and organic matter: distribution of aggregatesize classes and aggregate-associated carbon. Soil Science Society American Journal, v. 64, p. 681-689, 2000. Disponível em: <https://dl.sciencesocieties.org/publications/sssaj/abstracts/64/2/681>. Acesso em: 31 mar. 2019. http://dx.doi.org/10.2136/sssaj2000.642681x.

SOUZA, J. A.; LEITE, A. N. BEUTLER, Z. M. Comportamento de atributos físicos de um Latossolo Amarelo sob Agroecossistemas do Amazonas. Engenharia Agrícola, v.24, n.3, p.654-662, 2004. Disponível em: < http://www.scielo.br/scielo.php?script=sci abstract\&pid=S0100-69162004000300017\&lng=en\&nrm=iso\&t|ng=pt>. Acesso em: 31 mar. 2019. https://doi.org/10.1590/S0100-69162004000300017.

SPELLEBERG, I. F.; SAWYER, J.W.D. An introduction to applied biogeography. Cambridge: Cambridge University Press, 1999.

VALENTE, O. F.; GOMES, M. A. Conservação de nascentes: hidrologia e manejo de bacias hidrográficas de cabeceiras. Aprenda Fácil, Viçosa, 2005.

VARGEM ALTA. Plano de recuperação de cinco nascentes, sendo quatro na localidade de Prosperidade e uma em Vila Esperança, Vargem Alta - ES. Secretaria do meio ambiente, 2011.

VIEIRA, P. D. Análise do estado de conservação de nascentes do Ribeirão Dores do Turvo em Dores do Turvo, MG. [Trabalho de Conclusão de Curso]. Juiz de Fora, 2016. Disponível em: $<$ https://www.proceedings.blucher.com.br/article-details/anlise-do-estado-de-conservao-de-nascentes-doribeirodores-do-turvo-em-dores-do-turvo-mg-26768>. Acesso em: 31 mar. $2019 . \quad$ doi: http://dx.doi.org/10.5151/xveneeamb-098.

WAMMES, E. V. S.; UHLEIN, A.; CASTAGNARA, D. D.; FEIDEN, A.; PERINI, L. J.; STERN, E.; ZANELATO, F. T.; VERONA, D. A.; ULIANA, M. R. B.; ZONIN, W. J.; SILVA, N. L. S. Importância ambiental das áreas de preservação permanente e sua quantificação na microbacia hidrográfica da Sanga Mineira do município de Mercedes - PR. Revista Brasileira de Agroecologia, v. 2, n. 2, p. 1408-1411, $2007 . \quad$ Disponível em: <http://revistas.abaagroecologia.org.br/index.php/rbagroecologia/article/view/7064>. Acesso em: 17 fev. 2019. 


\section{Periódica Eletrânica}

